\title{
Enablers of psychosocial recovery in pediatric burns: perspectives from the children, parents and burn recovery support staff
}

Ashley Van Niekerk ${ }^{1,2^{*}}$, Roxanne Jacobs ${ }^{1,3}$, Nancy Hornsby ${ }^{1}$, Robyn Singh-Adriaanse ${ }^{1}$, Mathilde Sengoelge ${ }^{4}$ and Lucie Laflamme $e^{2,4}$

\begin{abstract}
Background: Pediatric burn injuries are a major cause of death and injury, occurring mainly in resource poor environments. Recovery from burns is widely reported to be constrained by physical, psychological, relationship and reintegration challenges. These challenges have been widely described, but not the enablers of psychosocial recovery. This is especially true in pediatric burn research, with few multi- perspective studies on the recovery process.

Methods: This qualitative study involved 8 focus group discussions (four with 15 children post-burn injury, four with 15 caregivers) and 12 individual interviews with staff working in pediatric burns that explored the psychosocial needs of children after a burn and the enablers of their recovery. Purposive sampling was utilized and recruitment of all three categories of participants was done primarily through the only hospital burns unit in the Western Cape, South Africa. The interviews focused on factors that supported the child's recovery and were sequentially facilitated from the child and the family's experiences during hospitalization, to the return home to family and friends, followed by re-entry into school. Thematic analysis was used to analyze verbatim interview transcripts.

Results: The recovery enablers that emerged included: (i) Presence and reassurance; indicating the comfort and practical help provided by family and close friends in the hospital and throughout the recovery process; (ii) Normalizing interactions and acceptance; where children were treated the same as before the injury to promote the acceptance of self and by others especially once the child returned home; and (iii) Sensitization of others and protection; signifying how persons around the child had assisted the children to deal with issues in the reintegration process including the re-entry to school.

(Continued on next page)
\end{abstract}

\footnotetext{
* Correspondence: ashley.vanniekerk@mrc.ac.za

'Violence, Injury and Peace Research Unit, South African Medical Research

Council and University of South Africa, Tygerberg, South Africa

${ }^{2}$ Institute for Social and Health Sciences, University of South Africa,

Johannesburg, South Africa

Full list of author information is available at the end of the article
}

(c) The Author(s). 2020 Open Access This article is licensed under a Creative Commons Attribution 4.0 International License, which permits use, sharing, adaptation, distribution and reproduction in any medium or format, as long as you give appropriate credit to the original author(s) and the source, provide a link to the Creative Commons licence, and indicate if changes were made. The images or other third party material in this article are included in the article's Creative Commons licence, unless indicated otherwise in a credit line to the material. If material is not included in the article's Creative Commons licence and your intended use is not permitted by statutory regulation or exceeds the permitted use, you will need to obtain permission directly from the copyright holder. To view a copy of this licence, visit http://creativecommons.org/licenses/by/4.0/. The Creative Commons Public Domain Dedication waiver (http://creativecommons.org/publicdomain/zero/1.0/) applies to the data made available in this article, unless otherwise stated in a credit line to the data. 
(Continued from previous page)

Conclusions: This study indicates that the psychosocial recovery process of children hospitalized for burns is enabled by the supportive relationships from family members, close friends and burn staff, present during hospitalization, the return home, and school re-entry. Support included comfort and physical presence of trusted others and emotional support; affirmation of the child's identity and belonging despite appearance changes; and the advocacy and protection for the re-entry back into the school, and more generally the community.

Keywords: Pediatric burn, Psychosocial recovery, Enablers, Children, Caregivers, Burn care providers

\section{Background}

Pediatric burns are a public health problem globally, concentrated in resource constrained regions where burns are highest in countries with low economic levels, such as in Sub-Saharan Africa [1]. A burn injury is considered one of the most traumatic, painful and stressful trauma experiences with disrupting effects on normal life [2-4] due to both the physical consequences of the injury and the stigma and discrimination associated with disability and in many instances, disfigurement [5]. Severe pediatric burns may lead to growth and development delays, behavioral and social problems within or outside the family [3], and schooling interruptions $[6,7]$. Survivors can suffer serious short- and long-term consequences among which wellknown psychological outcomes are post-traumatic stress disorder, depression, anxiety and sleep disturbances [7], increased aggressiveness, disturbed self-esteem and distressing memories of the burn [8]. These sequelae are likely exacerbated in adverse family and community settings, as is common in South Africa, where burn rates are high [1], where there is limited access to formal and specialized health, rehabilitation and support services [9], and where community stigmatization of survivors is a concern and may be widespread [10].

Studies on survivor perspectives as regards the prospects of recovery highlight how two main trauma phases come into play: the burn event (i.e. initial trauma of experiencing the burn) and the recovery itself. The latter encompasses a range of experiences within the child and between the child and the environment. These include: recurrent traumatization due to invasive medical procedures in wound management; scarring acting as a permanent reminder of the trauma even long after the wound has healed; bullying due to visible differences; behavioral changes such as avoidance, hyper- vigilance, and internalizing symptoms; and family reactions and adaptation in the form of overprotective parenting or child parentification [4].

Adequate and timely psychosocial ${ }^{1}$ support to victims is essential in order to maximize physical and

\footnotetext{
${ }^{1} 1$ Psychosocial refers to the mental, social, emotional and spiritual health of an individual with a typically complex interaction between these dimensions required for overall psychosocial well-being (59).
}

psychological recovery and reintegration back into the home, broader community and school [11]. The delivery of effective clinical and post-trauma interventions, including pain management interventions and early treatment of post-traumatic stress, thus play a determinant role in mitigating the consequences of these injuries. An increasing body of knowledge however focuses beyond the impairments in the injured child and emphasizes factors that enable recovery in a strengths-based approach [12]. This approach has often referred to the concept of resilience, i.e. the "process of overcoming the negative effects of risk exposure, coping successfully with traumatic experiences, and avoiding the negative trajectories associated with risks" [13]. Resilience studies recognize risk exposure but are focused on strengths rather than deficits and on understanding the processes that inform healthy development despite adversity [13]. Such studies have highlighted the interplay between a child's capacity to use opportunities, the capacity of the family and environment to provide resources to facilitate the child's recovery, and the contextually relevant interactions in the recovery process $[12,14,15]$. This provides a comprehensive picture of enablers at various levels, rather than focusing only on the personal characteristics of the vulnerable child's ability or inability to show resilience [16]. Innate enablers of recovery include a pragmatic attitude towards and acceptance of (the inevitability of) pain while progressing through rehabilitation, as well as acquiring hope and actively visualizing a future that includes set rehabilitation goals and a return to a previous or new vocation $[17,18]$. External enablers include support from family, friends, peers and professionals for dealing with the trauma and providing positive, uplifting relationships, as well as being informed about medical procedures and included in decisions [17, 18], and being shielded from stigma [19]. The supportive individual and relational factors to recovery have been documented for the trauma experienced after other causes of acute injuries [20] including adult burns [21]. However there have been few studies that have focused on the factors that enable the recovery of children after burns (e.g. [12], with few if any describing enabling factors as these may be pertinent to the immediate to longer term phases of 
recovery. The exploration of such factors is important for guiding enabler focused interventions and well suited to qualitative study.

The current study is thus one of the first qualitative investigations on the enablers important to pediatric burn recovery and over key phases in its progression. It is one of the few that combines perspectives from the child, parents and burn unit staff who have had direct, often close contact with the children over considerable periods of time [22]. This study aims to clarify these enablers, and thus contribute to this emerging knowledge of the factors that support the recovery process of burn injured children, especially in adverse settings.

\section{Methods}

\section{Setting}

The study took place in the Western Cape Province, South Africa, which has an estimated 6.5 million inhabitants [23]. Pediatric burns are a considerable public health problem in the Province; both in prevalence [24], and often severity, with a mortality of $3.6 / 100000$ person-years for those aged 15 years and younger in Cape Town, the provincial capital [25]. These mainly affect children from the poorest segments of the population and occur in and around homes with inadequate living conditions $[25,26]$.

\section{Design and participants recruitment}

The study is qualitative and combines three sets of data all addressing similar questions but dealing with three different groups of participants for complementary perspectives [27]: children who suffered a burn injury, caregivers of these children and professionals, and mainly hospital burn unit staff but also volunteers and non-governmental organization (NGO) staff interacting with them. Inclusion criteria for the children was (i) age 10 to 15 years; (ii) hospitalized in the burn unit for at least one night; 3 ) discharged for at least six months but not more than three years prior to contact with the research group. Children of this age group were chosen so that they had the required cognitive capacities, emotional maturity, independence, and verbal skills for engaging in discussions on their recovery experiences with minimal re-traumatization [28-30]. Table 1 presents characteristics of the participants with the level of detail adjusted to protect the privacy of the participants.

The three groups were recruited by means of purposive sampling through the Red Cross War Memorial Children's Hospital Burn Unit, the only specialized pediatric burns unit in Africa with the vast majority of patients from under-resourced, low income communities. Caregivers of 42 children were called by members of the research team (RJ, NH) to assess eligibility based on the inclusion criteria. Two child focus group discussions
(FGDs) and two caregiver FGDs were scheduled in this way. Snowballing techniques were then employed to obtain two more child FGDs and two caregiver FGDs via personal contacts with burn survivors in the local community. All caregivers and children who met the criteria and agreed to participate in the study were invited to attend an orientation session at the Red Cross Hospital which took place immediately before the FGDs, lasting between 10 to $15 \mathrm{~min}$. These sessions sought to fully brief participants and once parents had consented for their children to provide consent themselves, children and parents were separated to obtain individual consent to ensure that children did not feel obligated to participate. The recruitment of professionals was supplemented with a web-based search of staff from burn survivor support non-governmental organizations in South Africa.

\section{Data collection}

One interview guide to obtain feedback with the professionals and two facilitation guides, one for the child FGD and one for the parent FGD (see Additional file 1, 2 and 3) were consistently used throughout the interviews. The guides were designed prior to data collection and were based on a review of relevant literature combined with the research team's extensive experience in child burn epidemiology and prevention. The focus of the interview guides was on the psychosocial issues and needs of children after a burn injury and the enablers for recovery. Items for the child group were piloted on 2 healthy, non-injured children aged 12 and 14 years and no changes made.

Data collection took place from July 2017 to May 2018 for 12 individual interviews with the professionals and eight FDGs with 30 participants (15 children, 15 caregivers). Two interviewer-facilitators (drawn from AVN, RSA, NH, RJ) were present for each session, conducted at venues convenient to the participants. Permission and informed consent to audio-record the interviews/FDGs were obtained for each session, and conducted in three languages: English, Afrikaans and isiXhosa. The length of the interviews and FGDs ranged from approximately 28 to $84 \mathrm{~min}$. No changes were made to the interview guides with regards to the questions, which were firstly open ended and thereafter more specifically focused to enable the exploration of emerging issues. Therefore, varying and 'new' issues emerged with successive interviews/FGDs and this process was continued until we reached a consensus based the saturation of issues. The interviews were audio recorded, transcribed verbatim or intelligent verbatim and translated to English. Both interviewers checked the content of the transcriptions independently. 
Table 1 Participant characteristics

\begin{tabular}{|c|c|c|c|c|c|}
\hline \multirow[t]{2}{*}{ Target group } & \multirow{2}{*}{$\begin{array}{l}\text { Type of } \\
\text { interview }\end{array}$} & \multirow{2}{*}{$\begin{array}{l}\text { Occupation } \\
\text { (if } \\
\text { applicable) }\end{array}$} & \multicolumn{2}{|l|}{ Gender } & \multirow{2}{*}{$\begin{array}{l}\text { Length } \\
\text { (in } \\
\text { minutes }\end{array}$} \\
\hline & & & Female & Male & \\
\hline \multirow[t]{4}{*}{ Children (9-15 yrs) } & FGD 1 & & 4 & - & 42 \\
\hline & FGD 2 & & 4 & 1 & 39 \\
\hline & FGD 3 & & 2 & 1 & 63 \\
\hline & FGD 4 & & 2 & 1 & 28 \\
\hline \multirow[t]{4}{*}{ Family } & FGD 5 & & 4 & - & 72 \\
\hline & FGD 6 & & 5 & - & 46 \\
\hline & FGD 7 & & 3 & - & 77 \\
\hline & FGD 8 & & 3 & - & 75 \\
\hline \multirow[t]{12}{*}{ Professionals: Burns unit } & Interview 1 & Therapist & 1 & - & 35 \\
\hline & Interview 2 & Therapist & 1 & - & 84 \\
\hline & Interview 3 & Volunteer & - & 1 & 41 \\
\hline & Interview 4 & Psychologist & 1 & - & 53 \\
\hline & Interview 5 & Nurse & 1 & - & 68 \\
\hline & Interview 6 & Social worker & 1 & - & 76 \\
\hline & Interview 7 & Volunteer & 1 & - & 68 \\
\hline & Interview 8 & Volunteer & - & 1 & 36 \\
\hline & Interview 9 & Therapist & 1 & - & 28 \\
\hline & Interview 10 & Nurse & 1 & - & 32 \\
\hline & Interview 11 & Nurse & 1 & - & 60 \\
\hline & Interview 12 & NGO staff & 1 & - & 60 \\
\hline
\end{tabular}

\section{Data analysis}

Thematic analysis [31] was used to perform the data analysis. Data familiarization was performed by transcribing the data and reading and rereading the data, noting down initial ideas. Four of the authors from the research team (AVN, RSA, NH, RJ) performed data analysis with teams of two independently analyzing the interviews from the three informant groups, i.e. for the child (RJ, RSA); caregiver (RSA, NH) and health care provider interviews (NH, RJ), and an author (AVN) leading the verification process for each informant group. Interrater agreement was checked for initial codes via discussion between the coders in each team, with the full research team thereafter involved in the compilation of the sub-themes and themes. Themes were checked to ensure relevancy in relation to the codes. This process generated a thematic map' of the analysis. Then quotes from the participants were examined to portray the themes and sub-themes in the participants' own words. Consensus building took place within the research team to finalize this inductive process of maintaining consistency between the data presented and the formation of the themes and sub-themes.

\section{Results}

Recovery of the child after a burn takes place through key experiences occurring at the hospital, in the return home and in reintegration back into the community. Three themes emerged from the thematic analysis: (i) Presence and reassurance; from family, friends and hospital staff relationships; (ii) Normalizing interactions and acceptance; referring to those interactions where the child is treated the same as before the injury to promote the acceptance of self and by others; and (iii) Sensitization of others and protection; signifying the educational efforts directed at persons around the child to enable their support of the child in dealing with issues in the reintegration process, and strengthen their protection of the child from traumatization, e.g. through bullying. Figure 1 provides a visual representation of the three themes and eight sub-themes, and the phases, within which these were primarily manifest. The child and the persons most influential at the start of the recovery process in the burn unit are depicted at the core of the circle in grey, followed by the orange circle representing the child returning to the home and everyday neighborhood environment, and the yellow circle representing the wider community, especially the school 


\begin{tabular}{|c|c|c|}
\hline Sensitization of Others and Protection & $\begin{array}{l}\text { - Familiarizing peers and teachers } \\
\text { - Acting against peer bullying }\end{array}$ & - School Reentry \\
\hline $\begin{array}{l}\text { Normalizing Interactions and } \\
\text { Acceptance }\end{array}$ & $\begin{array}{l}\text { - } \text { Being treated as before } \\
\text { - Acceptance of oneself and by others } \\
\text { - Positive cognitive strategies }\end{array}$ & $\begin{array}{l}\text { - School Reentry } \\
\text { - Home Return }\end{array}$ \\
\hline Presence and Reassurance & $\begin{array}{l}\text { Presence, comfort and assistance } \\
\text { from family } \\
\text { - Care, reassurance from hospital } \\
\text { professionals } \\
\text { - Reconnecting with friends }\end{array}$ & $\begin{array}{l}\text { - Home Return } \\
\text { - Hospitalization }\end{array}$ \\
\hline
\end{tabular}

Fig. 1 Enablers of psychosocial burn recovery that emerged as themes and sub-themes from the thematic analysis

environment as the place where children spend the majority of their time.

\section{Theme 1: presence and reassurance}

Theme 1 is comprised of three sub-themes, i.e. (i) Presence, comfort and assistance from family; (ii) Care and reassurance from hospital professionals; and (iii) Reconnecting with friends. Key illustrations of each is provided below. All the groups highlighted the Presence, comfort and assistance from family; while Care and reassurance from hospital professionals were mostly indicated by health experts followed by parents and children; and Reconnecting with friends by both caregivers and children.

\section{Presence, comfort and assistance from family}

The physical presence, emotional and practical support started with family visits in the hospital's Burn Unit which comforted children and bolstered their feelings of being cared for, especially immediately after the burn. This physical presence was essential, especially from parents, and was complemented with reassuring communications and gestures that "things will be fine" (Parent, Interview 2, pg. 3). Furthermore, it was important for children to know that even if family could not physically be in the room, just the knowledge of their presence in the hospital facilitated both their physical and emotional recovery:

... Because my child, she was burned ... and like the next day ... most of my family came to see her. She wasn't close with them, but that day, when she was burned ... They came to see her and they weren't allowed here but they were standing outside, so that they can see her and that, I promise you that ... was helping her to heal herself in the hospital .... [Parent, Interview 1 pg. 9-10].
Supplementing this presence of family was the significance of practical everyday help which was pervasive and stood out in the children's accounts of their experiences especially on their return home from hospital. Family members, particularly siblings, would e.g. take over the children's chores, such as doing the dishes, on occasion the laundry, and preparing food. One child drew attention to his sister's emotional support when he felt unwell and even helpless; another's would be physically affectionate by hugging him and buying him treats; while others highlighted the resumption of play with siblings; some, the household chores done by siblings, including one by sibling who uses a wheel-chair; and another the physical escort provided by a sibling in guiding him around while his vision was still impaired by bandaging.

\section{Care and reassurance from hospital professionals}

Hospital care providers provided not only physical healing support but also through a nurturing role intentionally provided emotional support to the children and parents as they adjusted to the shock of the burns and the painful hospital procedures (e.g. initial burn dressing changes). They also allowed children to participate in decision-making around aspects of their medical care, helped with practical matters such as calls on behalf of the child to the mother, and reassured the child on the continuity of care even with staff rotations or departures. One child highlighted the role that the nurses and doctors had played as central to survival:

... When I left the hospital, then I thanked all the nurses and the doctors for helping me. And for when they carried me out ... and for all the work they have done, it was very beautiful...If it wasn't for them, I would not have made it. [Child 1, FGD 3, p.8]. 
This supportive role was supplemented by ongoing pain management identified by experts as underpinning the child's ability to cope with burn wound care. Pain control alleviated emotional distress, strengthened the experience of coping, and offered the child some experience of control:

The other thing, we [were] looking at in pain management ... so, one of the things we identified was giving the child back his control ... where the child is allowed then to maybe take off his own dressing [Professional, Interview 5, pg. 6].

The children's anxieties were lessened when hospital staff engaged with the children and took the time to speak to them directly. Hospital volunteers, particularly those who are burn survivors, were of particular assistance in engaging the child in the recovery process, specifically through reading and where possible play, thus providing comfort to the child but also serving as an example of survival and coping, and thus reducing anxiety.

\section{Reconnecting with friends}

When the children returned home they experienced stigmatization and mocking by others, but also the importance of friends in strengthening their ability to cope. The significance of both instrumental support and affection was highlighted by the children and experienced through a warm welcome back home, gift-giving and gestures of friendship, in a number of cases from friends made in hospital, but especially from those that had been regarded as best friends. The resumption of play activities was important, and the company when introduced back into the neighborhood. The significance of these friendships was also echoed by the parents who elaborated that although some children were initially resistant to reengaging with friends, maintaining friendships despite the occurrence of the burn was crucial:

... Her friends she always played with at home, those. Even, even, even if she says no, friends must come. Even if they come every day, even if they come every second day or whatever. But as long as she, she can see in her mind, her mind tells [and she] can see it: 'No, they want to be my friends'. [Parent 3, FGD 1].

\section{Theme 2: normalizing interactions and acceptance}

Theme 2 includes three sub-themes: (i) Being treated as before; (ii) Acceptance of oneself and by others; and (iii) Positive cognitive strategies, each of which is demonstrated below. Caregivers highlighted Being treated as before; while Acceptance of oneself and by others were mostly indicated by health experts; and Positive cognitive strategies by children followed by caregivers.

\section{Being treated as before}

The children relied on family and close friends to engage them to participate in everyday, social activities, such as holding the child's hand in public, visiting the mall and places of entertainment, taking photographs of the child, and having sleepovers with friends:

... I would ask her to go with, avoiding her being lonely. We would take pictures at the mall avoiding the feeling of her thinking that I'm no longer loving her since she got burnt. .... I would make sure that I also style her hair up whenever I'm styling her other sister to avoid treating my children differently ... I wanted her to see that to me she's still the child that she was even if she got burnt. [Parent 1, Interview 4].

\section{Acceptance of oneself and by others}

The health workers affirmed the acceptance by others' as an important step towards the child's self- acceptance. In particular, one father had recognized and asserted his daughter's value which, in turn, encouraged her selfacceptance and hope for a life after the burn:

I must say that her inner strength ... that she found within herself ... was due to the fact that her dad accepted and acknowledged his beautiful little girl and because he acknowledged it, she acknowledged it, that she is the little girl who is alive, that can still live and be out there ... and have a life. [Health worker Interview 5].

Another child made a conscious effort to see himself in the mirror and channel his own resources inwardly to promote self-acceptance:

But with the boy that I referred to earlier, he then made a point to always go to the mirror and look at himself and really got better ... he really did get better ... [Health worker Interview 5].

\section{Positive cognitive strategies}

Also important were the children's use of individual cognitive coping strategies to bolster the child and indirectly others' acceptance of the changes brought about by the burn injury. These centered around positive self-talk around the child's perseverance, maintaining physical strength, and managing their fears, for example:

You can just focus on one thing at a time. Not too much, like um ... if you come out of hospital, just 
keep yourself relaxed. Don't worry about what's going to happen tomorrow. [Child 4, FGD 1].

\section{Theme 3: sensitization of others and protection}

Theme 3 included two sub-themes: (i) Familiarizing peers and teachers; and (ii) Acting against bullying. Caregivers, but also experts and children highlighted the importance of Familiarizing peers and teachers; while mostly children and some caregivers foreground Acting against bullying.

\section{Familiarizing peers and teachers}

A supportive school environment in which the child feels a sense of belonging was identified as an important factor in recovery. Parents provided information about their child's condition and needs to enable the advocacy role of school-teachers and principals:

You know the principal called an assembly to inform the whole school about him and encouraging them not to laugh, instead be supportive when he comes back to school. That made the process much easier for him. [Parent FGD 2].

\section{Acting against bullying}

The child's need to be protected from peer bullying was prominently reported on by both the children and their caregivers. Both parents and teachers at school would comfort or reassure the returning child around incidents of being laughed at, mocked or bullied, and offer practical advice and steps to ease the child's return through e.g. minimizing obvious scars; while teachers and school principals would act against bullying by following up complaints, advocating to others on the child's behalf, and educating the general school population and parents. In response to being laughed at in school, one child's teacher educated the parents at the school on the consequences of the burn injury:

So he went again to school and on the third day his teacher called me concerned about him. She explained to me that all parents need to be called to a meeting where they can be educated about burns because the children were laughing at him every day. The teacher called all parents as she didn't want to exclude certain children. So after that meeting my child was never bothered by other children at school. [Parent FGD 4].

\section{Discussion}

This study highlights experiences of the supportive relationships that played a key role during hospitalization, the return home, and re-entry to school. Immediately after the trauma, it was the close family, supported by professional health staff, siblings and even initial visits by peers, that were key to providing physical presence, comfort and immediate affective support for the stabilization or psychological first aid of the child [32]. The return home, while initially experienced with relief, brought to the fore to the child and its immediate social network, the challenge of recognizing and integrating any changes to appearance or functionality, as it has for adolescents [33] and older survivors [21]. The longer-term psychosocial recovery was in this study centred around the preparations for re-entry into the school and anticipated experiences with the school peer community, where adult intervention and the placement of safeguarding measures to counter bullying were reported as critical for the reassurance and protection of the child [34].

This study draws attention, in the immediate aftermath of the trauma, to the salience of the family's physical presence and unconditional affective support. The study highlighted parental and family presence, acts of comfort and emotional support, the preparation of extended family, and instrumental support. This helped alleviate the child's anxiety, facilitated a sense of control over the situation, and assisted the child to make initial meaning of the trauma experience, as also indicated in other studies [33, 35, 36]. Here, the conscientious care by hospital staff beyond their clinical expertise including pain management, emphasized the interpersonal sensitivity and engagement with the child, especially where family members were not present. The latter was not uncommon, with parental presence often restricted whether due to economic barriers, or occupational and family pressures. Hospital volunteers, particularly those who are themselves burn survivors, appeared to be important as a manifestation of successful survival and coping of their own trauma. The importance of such emotional responsiveness, support, and empathy with the child's experience, especially by parents or trusted parental figures, but also professional health staff, and installation of hope by volunteer burn survivor staff, was reported in this study as containing the alarm, confusion and distress that accompanied the child's pain. Family support has already been indicated as a leading determining factor of psychosocial adjustment for child burn survivors [4, 37, 38], with parents offering comfort and both practical and emotional support to the child in an unfamiliar environment and especially during medical procedures [35]. Peer and sibling support has also been recognized as important in the recovery of the older child and adolescent, for whom acceptance by the peer group has been described as critical for psychosocial development [37]. In the hospital phase, it was the instrumental and emotional support and affection offered primarily by siblings, but also those that had been 
regarded as best friends and in a number of cases from friends made in hospital. The significance of such supportive relationships has also been echoed in child [39, 40], adult burn [41], and also other trauma recovery and resilience studies $[42,43]$. In this study, the affection and support from family and friends, and the respect and compassion of hospital staff reassured and comforted the children, installed hope, and thus bolstered their endurance especially of the physical pain and helplessness highlighted immediately after the injury $[19,35]$, a form of psychological first aid [32].

Despite the initial relief after discharge a new set of challenges emerged and manifest when back at home, especially awareness of permanent physical, functional and body image changes, and the implications of these for social identity and self-esteem [19]. The removal of the dressings and over time recognition of the permanence of scars was reported here, as elsewhere [11, 37], to confront the child with the changes to their appearance that may initially have been ignored, and the feared implications of these for the child's identity, esteem, and social relationships. This study highlighted that the recognition of the changes to appearance; the mobilization by the child of cognitive strategies to support post-burn social and daily activities; and the sharing of activities that had been enjoyed before, all contributed to the child's post-burn adjustment. The appearance changes suffered have been reported elsewhere within a struggle for self-acceptance centered around the stark contrast of the 'inner self' with that of the now disfigured outer appearance, with the child needing to recognize that despite the external changes, their unique identity and inner self had or could endure and retain its value $[33,44]$. The use of cognitive skills is aligned with indications that higher cognitive abilities are used to understand the burn incident, minimize negative self-attributions, and prepare for treatment and recovery experiences, all of which precede better social adjustment, coping and faster healing [12, 15]. The return to previous 'normal' interpersonal and recreational activities, especially when in public places and with neighborhood and later on school peers, has been reported to counter social isolation [37], reestablish with support a social presence and social competence, and bolster self-esteem [12]. This study indicates that such social and interpersonal engagements are necessary, especially when accompanied with publicly affirming experiences, along with positive cognitive strategies, to support an acceptance of the physical changes that had occurred. The latter psychological process has been identified as key to the child's coping with the consequences of the trauma and the personal transformation required for recovery [12, 33], and preceded by the child's positive reframing of the trauma and its consequences to "reconstruct their idea of themselves, their normality and their future" [22].

The child's longer-term psychosocial recovery was in this study, as in others, reported as largely dependent on the survivor's positive, supportive interactions with others, with these having promoted an easier reintegration first into their homes, and thereafter into their neighborhood, school and community at large [4, 11]. This study highlighted the importance of protective peer relationships to ease the re-entry of the child to school, buffer against the interpersonal challenges that would face the returning child, and support the child's participation in school activities, including those such as sport, where the child's visible injuries and scarring may be exposed and serve as a focus for stigmatization and bullying (see e.g. 4). This study thus recognized the school as an important setting for the returning child's reengaging with peers, especially now in the absence of the previous direct support of hospital staff or parents, and as required for the formation and consolidation of peer and intimate relationships, the further development of the child's self-image and social identity, and their academic competencies $[45,46]$. While protective peer relationships with school peers was recognized, the reassurances, advice, corrective actions and proactive protection by educational authorities was also highlighted, along with the attendant need by such advocates for information on the child's health and support needs, to ensure effective and supportive ways to foster the child's school re-entry, even in the adverse school environments common in South Africa [46, 47]. The importance of schools designating an adult to which burn-surviving children can report bullying [48] is aligned to the role of adults highlighted here, while other disability studies have indicated a preference for support from peers above parental and teachers [49]. This advocacy role combined with the receptivity of school staff and peers to the returning child served to buffer against school re-entry concerns, and complemented the school reintegration enablers reported elsewhere, including the child's emotional and interpersonal capacities and ongoing home support [50].

This study has a number of implications for the strengthening of practice directed at the recovery of burn injured children. Burn care facilities can, and in many cases do enable an emotionally supportive environment, involving wherever possible the family and the child in the management of treatment and rehabilitation, and facilitating the physical presence of families during hospitalization. Burn care in South Africa as in other under resourced settings, is however variable in terms of facilities and services, organization, staffing and workload. These facilities are furthermore predominantly emergency-driven and thus, along with South African health facilities in general, have been criticized for not 
sufficiently integrating the psychological, spiritual and social integration and recovery domains into physical resuscitation and rehabilitation plans [51]. This affects both in-hospital and post-discharge support, although the situation for post-discharge support is likely to be more precarious in under-resourced settings. This study highlighted strengthened post-discharge interpersonal support, and for this to include the child's need for support to emotionally integrate the changes to appearance or functionality, support for the consolidation of the child's post trauma identity, and for the positive reintegration into the neighborhood and in the school. However, this again must be considered within the context of generally overburdened health and social systems, where the affected family is expected to resume control over their own lives often with minimal input from specialized support staff, from the social and health [11], and educational systems [50].

\section{Strengths and limitations}

This study is one of the first qualitative studies on early burn recovery and enablers, from the perspectives of the child, parent figures and staff [22], a combination which has been motivated for in child resilience research [27]. There is a contextualization of the known barriers to recovery, specific to the South African experience, but with an important emphasis on the enablers to recovery. These enablers were identified through perspectives offered from a range of people who have very close experience with the process. The complexities of the recovery experience were explored by an experienced research team with previous experience of qualitative and indepth interviews with burn survivors. It is important to note that the interview guide was organized in a chronological manner so as to follow the process from hospital discharge to community reintegration, but also allowing for the authors' emerging thoughts and reflections. The orientation, interview and debriefing conditions involved the detailed description of the purpose of study which was well understood from participants and contributed to a comfortable situation and environment. These interviews were in the home language of participants, to promote comfort, especially for the children, and to avoid misinterpretation.

Yet the study has a number of limitations. There may be some uncertainty as regards whose voice and what counts 'most' as enablers, as there were a number of enablers identified but how relatively important they are is not reflected in the material. There may also be an unequal representation of the situations that were meant to be covered, i.e. from the hospital time up to school reintegration, with the study e.g. not involving informants from all perspectives from the school. In addition, we know about school time from 'projections' and indirect accounts rather than from school peers and teachers themselves, and thus perhaps not all themes from this phase may be well covered. Also, we interacted with participants, in particular children, who were cared for in a highly regarded, specialized hospital setting in the Western Cape, and one of the few in the country with extensive experience in both the physical management and more importantly the psychosocial support of burn survivors that is aligned to the scientific literature on trauma recovery process [52]. This however, may have obscured concerns that may be more prevalent in other hospitals that have less specialized capacity.

\section{Conclusion}

The study highlighted relational resources as key enablers of a child's recovery after burns. Sensitive affective support and physical presence of key relationships, especially early on in the process, are crucial. The support for acceptance by the child and others of the visible changes in appearance causing issues with self-identity and self-esteem were emphasized, especially on the return home, as was the advocacy and protection required for the child's re-entry back into the school and community.

\section{Supplementary information}

Supplementary information accompanies this paper at https://doi.org/10. 1186/s12887-020-02180-z.

Additional file 1:. Semi-Structured Interview Guide with Professionals

Additional file 2:. Child and Adolescent Focus Group Discussion Interview Schedule

Additional file 3:. Parent and Legal Guardian Focus Group Discussion Interview Schedule

\section{Abbreviations}

NGO: Non-governmental organization; FGD: Focus group discussion.

Acknowledgements

The authors wish to thank the children, parents, caregivers and professionals in the burn injury field for their study participation.

\section{Authors' contributions}

AVN, MS and LL conceptualized the study, the data collection instruments and collection procedures. RJ and $\mathrm{NH}$ developed the data collection instruments and collection procedures and with AVN and RSA collected data. All authors were involved in the data analysis, interpretation and write up of the manuscript. All authors have read and approved the manuscript.

\section{Funding}

The study was funded by the South African Medical Research Council, the Karolinska Institutet, the South African National Research Foundation and the Swedish Foundation for International Cooperation in Research and Higher Education (STINT; grant number STINT150915142579). The funders had no role in the design of the study or the collection, analysis, interpretation of data, writing of or the final decision to publish the manuscript.

Availability of data and materials

This is a qualitative study mirroring the context of the Western Cape, South Africa with a very small population of pediatric burn survivors, their caregivers and burn care specialists. Making the full data set publicly 
available could potentially be a breach to the privacy that the participants were promised upon request for participation. Also, our ethics approval from the South African Medical Research Council and the University of Cape Town's Faculty of Health Sciences Ethics Committees was granted based on the anonymity of the individuals consenting to participate. Due to these conditions, the authors are unable to make the full transcripts available to a wider audience. Excerpts of specific segments of the text will be reviewed for any potentially identifying details and made available to fellow researchers or reviewers who complete a data sharing agreement and abide by strict confidentiality protocols. In line with the information given to the participants and restrictions set by the two ethical committees, access to the full transcripts are only available to the involved researchers. Data requests may be sent to the corresponding author, AVN, at ashley.vanniekerk@mrc.ac.za.

\section{Ethics approval and consent to participate}

Ethical approval for the study was granted by the South African Medical Research Council Ethics Committee (EC034-11/2016) and the University of Cape Town's Faculty of Health Sciences (225/2017). Written informed consent from the participants was obtained prior to each interview or FGD. Written informed consent was obtained from a parent or guardian for all participants under 16 years old. Each child completed a debriefing questionnaire at the end of the FGD to determine any need for referral. Furthermore, the child and caregiver participants were provided with the contact number of a social worker available for questions which required therapeutic answers. Three children and two caregivers were actively referred for psychological support after the FGDs.

\section{Consent for publication}

Not applicable.

\section{Competing interests}

The authors declare that they have no competing interests.

\section{Author details}

${ }^{1}$ Violence, Injury and Peace Research Unit, South African Medical Research Council and University of South Africa, Tygerberg, South Africa. ${ }^{2}$ Institute for Social and Health Sciences, University of South Africa, Johannesburg, South Africa. ${ }^{3}$ The Alan J. Flisher Centre of Public Mental Health, University of Cape Town, Cape Town, South Africa. ${ }^{4}$ Department of Public Health Sciences, Karolinska Institutet, Stockholm, Sweden.

\section{Received: 24 October 2019 Accepted: 27 May 2020}

Published online: 09 June 2020

\section{References}

1. Sengoelge M, El-Khatib Z, Laflamme L. The global burden of child burn injuries in light of country level economic development and income inequality. Prev Med Rep. 2017;6:115-20.

2. Pardo GD, Garcia IM, Marrero FD, Cia T. Psychological impact of burns on children treated in a severe burns unit. Burns. 2008:34:986-93.

3. Bakker A, Maertens KJ, Van Son MJ, Van Loey NE. Psychological consequences of paediatric burns from a child and family perspective: a review of the empirical literature. Clin Psychol Rev. 2013;33(3):361-71.

4. McGarry S, Elliot C, McDonald A, Valentine J, Wood F, Girdler S. Paediatric burns: from the voice of the child. Burns. 2014;40:606-15.

5. World Health Organization. Burns Factsheet. 2016. Report No.: http://www. who.int/mediacentre/factsheets/fs365/en/.

6. Steenkamp WC, Albertyn R. Psychosocial factors that influence the outcome of burn treatment. South Africa Med J CME. 2012;29(9):424-6.

7. Van Baar MA, Polinder S, Essink-Bot ML, Van Loey NE, Oen IM, Dokter J, et al. Quality of life after burns in childhood (5-15 years): children experience substantial problems. Burns. 2011;37(6):930-8.

8. Zeitlin RE. Long-term psychosocial sequelae of paediatric burns. Burns. 1997; 23(6):467-72.

9. Albertyn R, Bickler S, Rode H. Paediatric burn injuries in sub Saharan Africaan overview. Burns. 2006;32(5):605-12.

10. Dekel B, Van Niekerk A. Young women's stories of their (re) negotiation of appearance, identity and psychological adjustment, and social reintegration following burn injury. Burns. 2018;44(4):841-9.
11. Pavoni V, Gianesello L, Paparella L, Buoninsegni LT, Barboni E. Outcome predictors and quality of life of severe burn patients admitted to intensive care unit. Scand J Trauma Rescusc Emerg Med. 2010;18(24):24.

12. Kornhaber R, Bridgman $H$, McLean $L$, Vandervord J. The role of resilience in the recovery of the burn-injured patient: an integrative review. Chron Wound Care Manage Res. 2016:3:41-50.

13. Fergus S, Zimmerman MA. Adolescent resilience: a framework for understanding healthy development in the face of risk. Annu Rev Public Health. 2005;26:399-419.

14. Ungar M. Social ecologies and their contribution to resilience. In: Ungar M, editor. The social ecology of resilience: a handbook of theory and practice. New York: Springer; 2012. p. 13-31.

15. Abrams TE, Ratnapradipa D, Tillewein H, Lloyd AA. Resiliency in burn recovery: a qualitative analysis. Soc Work Health Care. 2018;57(9):774-93.

16. Ungar M. Resilience across cultures. Br J Soc Work. 2008;38(2):218-35.

17. Kornhaber R. Roads to recovery: adult burn survivors' lived experience of rehabilitation. Adelaide: University of Adelaide; 2013.

18. Ren Z, Chang W, Zhou Q, Wang Y, Wang H, Hu D. Recovery of lost face of burn patients, perceived changes, and coping strategies in the rehabilitation stage. Burns. 2015;41(8):1855-61.

19. Ravindran $V$, Rempel GR, Ogilvie L. Parenting burn-injured children in India: a grounded theory study. Int J Nurs Stud. 2013;50:786-96.

20. Alisic E, Boeije HR, Jongmans MJ, Kleber RJ. Supporting children after singleincident trauma: parents' views. Clin Pediatr. 2012;51(3):274-82.

21. Attoe C, Pouds-Cornish E. Psychosocial adjustment following burns: an integrative literature review. Burns. 2015;41:1375-84.

22. Johnson RA, Taggart SB, Gullick JG. Emerging from the trauma bubble: redefining 'normal' after burn injury. Burns. 2016;42(6):1223-32.

23. Statistics South Africa. Statistical release mid-year population estimates; 2017. Report No.: http://www.statssa.gov.za/publications/P0302/P03022017.pdf.

24. Blom L, Klingberg A, Laflamme L, Wallis L, Hasselberg M. Gender differences in burns: a study from emergency centres in the Western cape. South Africa Burns. 2016;42(A):1600-8.

25. Rode H, Berg A, Rogers A. Burn care in South Africa. Ann Burns Fire Disasters. 2011;XXVI(1):7-8.

26. Van Niekerk $A$, Laubscher $R$, Laflamme L. Demographic and circumstantial accounts of fatal burn injuries in Cape Town: A register-based cross-sectional study. BMC Public Health. 2009;9(37). https://doi.org/10.1186/1471-2458-9-374.

27. Theron L. Adolescent versus adult explanations of resilience enablers: a south African study. Youth Soc. 2020;52(1):78-98.

28. Kassam-Adams N, Newman E. Child and parent reactions to participation in clinical research. Gen Hosp Psychiatry. 2005;27(1):29-35.

29. Finkelhor D, Vanderminden J, Turner H, Hamby S, Shattuck A. Upset among youth in response to questions about exposure to violence, sexual assault and family maltreatment. Child Abuse Negl. 2014;38(2):217-23.

30. Hambrick E, O'Connr B, Vernberg E. Interview and recollection-based research with child disaster survivors: participation-related changes in emotion and perceptions of participation. Psychol Trauma. 2016;8(2): 165-71.

31. Braun V, Clarke V. Using thematic analysis in psychology. Qual Res Psychol. 2006;3(2):77-101.

32. Hobfoll SE, Watson P, Bell CC, Bryant RA, Brymer MJ, Friedman MJ, et al. Five essential elements of immediate and mid-term mass trauma intervention: empirical evidence. Psychiatry. 2007;70(4):283-315.

33. Lau U, Van Niekerk A. Restorying the self: an exploration of young burn survivors' narratives of resilience. Qual Health Res. 2011;21(9):1165-81.

34. Rimmer R, Fornaciari G, Foster K, Bay C, Wadsworth M, Wood M, et al. Impact of pediatric residential burn camp experience on burn survivors' perceptions of self and attitudes regarding the camp community. J Burn Care Res. 2007;28(2):334-41.

35. Egbert MR, de Jongh AE, Hofland HE, Geenen R, Van Loey NE. Parental presence or absence during paediatric burn wound care procedures. Burns. 2018;44:840-60.

36. Whitehurst E. Parental presence within the post-anaesthetic care unit. Br J Anaesthetic Recovery Nursing. 2002;3(3):4-9.

37. De Sousa A. Psychological aspects of paediatric burns: A clinical review. Ann Burns Fire Disasters. 2010;XXIII(3):155-9.

38. Moi AL, Gjengedal $E$. The lived experience of relationships after major burn injury. J Clin Nurs. 2014;23:2323-31.

39. Lehna C. Sibling experiences after a major childhood burn injury. Pediatr Nurs. 2010;36:245-52. 
40. Lehna C. Stigma perspective of siblings of children with a major childhood burn injury. J Am Acad Nurse Pract. 2013;25:557-62.

41. Martin L, Byrnes M, McGarry S, Rea S, Wood F. Posttraumatic growth after burns in adults: an integrative literature review. Burns. 2017;43:459-70.

42. Ungar M. The differential impact of social services on young people's resilience. Child Abuse Negl. 2018:78:4-12.

43. Van Breda AD, Theron LC. A critical review of South African child and youth resilience studies, 2009-2017. Child Youth Serv Rev. 2018;91:237-47.

44. Blakeney P. School reintegration. J Burn Care Rehabil. 1995;16(2):180-7.

45. Madan-Swain A, Katz ER, LaGory J. School and social reintegration after a serious illness or injury. In: Brown RT, editor. Handbook of pediatric psychology in school settings. New Jersey: Lawrence Erlbaum Associates; 2004.

46. Pan R, Dos Santos BD, Nascimento LC, Rossi LA, Geenen R, Van Loey NE. School reintegration of pediatric burn survivors: an integrative literature review. Burns. 2018:44(3):494-511.

47. Burton P, Leoschut L. School violence in South Africa: results of the 2012 national school violence study. Centre for Justice and Crime Prevention: Cape Town; 2013.

48. Rimmer RB, Foster KN, Bay CR, Floros J, Rutter C, Bosch J, et al. The reported effects of bullying on burn-surviving children. J Burn Care Res. 2007;28(3): 484-9.

49. Bourke S, Burgman I. Coping with bullying in Australian schools: how children with disabilities experience support from friends, parents and teachers. Disabil Soc. 2010;25(3):359-71.

50. Horridge G, Cohen K, Gaskell S. BurnEd: parental, psychological and social factors influencing a burn injured child's return to education. Burns. 2010;26: 630-8.

51. De la Porte A. Spirituality and healthcare: towards a people-centred healthcare in South Africa. HTS Teologiese Studies/Theological Studies 2016;72(4):a3127.

52. Albertyn R, Numanoglu A, Rode H. Pediatric burn care in sub-Saharan Africa. Afr J Trauma. 2014;3(2):61-7.

\section{Publisher's Note}

Springer Nature remains neutral with regard to jurisdictional claims in published maps and institutional affiliations.

Ready to submit your research? Choose BMC and benefit from:

- fast, convenient online submission

- thorough peer review by experienced researchers in your field

- rapid publication on acceptance

- support for research data, including large and complex data types

- gold Open Access which fosters wider collaboration and increased citations

- maximum visibility for your research: over $100 \mathrm{M}$ website views per year

At $\mathrm{BMC}$, research is always in progress.

Learn more biomedcentral.com/submissions 